\title{
Rosiglitazone attenuates the metalloprotease/anti- metalloprotease imbalance in emphysema induced by cigarette smoke: involvement of extracellular signal-regulated kinase and NFKB signaling
}

\author{
This article was published in the following Dove Press journal: \\ International Journal of COPD \\ 7 April 2015 \\ Number of times this article has been viewed
}

\section{Gang Hou \\ Yan Yin \\ Dan Han \\ Qiu-yue Wang \\ Jian Kang}

Department of Respiratory Medicine, the First Hospital of China Medical

University, Shenyang, People's

Republic of China
Correspondence: Qiu-yue Wang Department of Respiratory Medicine the First Hospital of China Medical University, I 55 Nanjing North Street, Shenyang 1 1 0004, People's Republic of China

Tel +862483282219

Fax +86 2483282002

Email qywangcmu@I26.com
Objective: We investigated how rosiglitazone attenuated cigarette smoke (CS)-induced emphysema in a rat model. In particular, we focused on its possible effects on the imbalance between metalloprotease (MMP) and anti-MMP activity, mitogen-activated protein kinase (MAPK) phosphorylation, and nuclear factor kappa-light-chain-enhancer of activated B cell $(\mathrm{NF \kappa B})$ signaling pathway over-activation.

Methods: A total of 36 Wistar rats were divided into three groups ( $n=12$ each): animals were exposed to CS for 12 weeks in the absence (the CS group) or presence of $30 \mathrm{mg} / \mathrm{kg}$ rosiglitazone (the rosiglitazone-CS [RCS] group); a control group was treated with the rosiglitazone vehicle only, without any CS exposure. Histopathology of lung tissue in all groups was evaluated to grade severity of the disease. Expression levels of peroxisome proliferator-activated receptor $\gamma$ (PPAR $\gamma$ ), MMP2, and MMP9 in lung tissue were determined and compared using Western blotting and immunohistochemistry. Activation of MAPKs, NFKB, and the nuclear factor of kappa light polypeptide gene enhancer in B-cell inhibitor, alpha $(\mathrm{I} \kappa \mathrm{B} \alpha)$ phosphorylation in lung tissue was examined by Western blotting.

Results: Emphysema-related pathology, based on inter-alveolar wall distance and alveolar density, was less severe in the RCS group than in the CS group. Compared with the CS group, levels of PPAR $\gamma$ were higher in the RCS group, and levels of MMP2 and MMP9 proteins were lower in the RCS rats. Levels of activated MAPKs and NFKB were also lower, while the

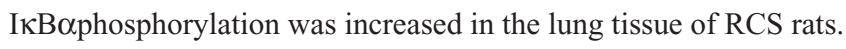

Conclusion: Our findings suggest that oral administration of rosiglitazone attenuates the metalloprotease activity induced by CS, and the underlying mechanism might involve the activation of signaling pathways dependent on MAPKs or NFKB. Our results further suggest that PPAR $\gamma$ contributes to the pathogenesis of emphysema as well as airway inflammation induced by CS. Keywords: emphysema, chronic obstructive pulmonary disease, matrix metalloprotease9, matrix metalloprotease2, PPAR, NFאB

\section{Introduction}

Chronic obstructive pulmonary disease (COPD) of the lungs involves irreversible airway obstruction and abnormal, chronic inflammation of the airway. ${ }^{1}$ Smoking is a key risk factor of COPD: it strongly induces the release of inflammatory mediators, including oxidants and proteases, which ultimately trigger chronic airway inflammation and emphysema. ${ }^{2}$ Emphysema is a complication of COPD that arises when chronic inflammation in the lung destroys the normal balance between the activity of metalloproteases like matrix metalloproteinases (MMPs) and the activity of anti-metalloproteases 
like tissue inhibitor of metalloproteinase (TIMPs), resulting in abnormally enhanced MMP activity. ${ }^{3,4}$

Smoking cessation may partially restore pulmonary function and lung density in patients with stable COPD, ${ }^{5,6}$ whereas co-administration of anti-inflammatory drugs is a must in order to control chronic airway inflammation and progression of emphysema. Not all patients with COPD respond equally well to the medical treatment; for example, patients without emphysema respond much better than those with severe emphysema do. ${ }^{7}$

Efforts have been made to identify more universally effective anti-inflammatory drugs to treat COPD, and researchers' interest has been gradually focused on peroxisome proliferator-activated receptors (PPARs). These ligand-activated transcription factors belong to a nuclear hormone receptor family ${ }^{8}$ and appear to regulate immune and inflammatory responses by inhibiting the expression of proinflammatory genes. ${ }^{9,10}$ The most extensively studied PPAR subtype is PPAR $\gamma$, which is involved in a wide spectrum of lung diseases, including pulmonary vascular disease, acute lung injury, asthma, and lung cancer. ${ }^{11-14}$ PPAR $\gamma$ agonists have immunomodulating effects that lead to reduced secretion of inflammatory cytokines in articular cell culture or experimental models of arthropathy. ${ }^{15,16}$ They also repress the synthesis of extracellular matrix components in various cell types, such as collagen synthesis by thiazolidinediones in mesangial cells from diabetic rats ${ }^{17}$ and Wy14643 synthesis in hepatic stellate cells from rats with cholestatic liver fibrosis. ${ }^{18}$ Recently, PPAR $\gamma$ agonists have begun to be used as an anti-inflammatory therapy for COPD..$^{10,15}$

One unresolved question is whether PPAR $\gamma$ agonists help reverse the metalloprotease/anti-metalloprotease imbalance associated with emphysema. In this study, we used a rat model of smoking-induced emphysema to examine how rosiglitazone (Sigma-Aldrich Co., St Louis, MO, USA), one of the PPAR $\gamma$ agonists, affected COPD pathology. We examined whether rosiglitazone altered the metalloprotease/ anti-metalloprotease imbalance, and explored the molecular mechanism underlying the imbalance.

\section{Materials and methods}

\section{Animal model}

All experiments were conducted in accordance with the guidelines of the Research Ethics Committee of China Medical University. Male Wistar rat weanlings (weighing 170-210 g) were obtained from the Laboratory Animal Center of China Medical University and randomly assigned into three groups with 12 animals in each group. The cigarette smoke (CS) group was exposed to smoke from 16 commercial cigarettes (Altria Group Inc, Richmond, VA, USA); each of these cigarettes contained $0.9 \mathrm{mg}$ nicotine, $14 \mathrm{mg} \mathrm{CO}$, and $12 \mathrm{mg}$ tar oil, according to the manufacturer's specifications. Animals were exposed to smoke (scope, $8 \% \mathrm{v} / \mathrm{v}$ ) with the cigarette filters removed for 30 minutes, twice a day, 6 days per week for 12 weeks. The rosiglitazone-CS (RCS) group was exposed to CS in the same way as the CS group but in the presence of rosiglitazone, intragastrically administered once daily (30 mg/kg, dissolved in normal saline). The control group and CS group received a daily orally administered injection of saline vehicle without any smoke.

At the end of the 12th week, rats were sacrificed by exsanguination and lungs were excised. The right upper lobes were removed and stored at $-80^{\circ} \mathrm{C}$, and the right median lobes were embedded in paraffin.

\section{Lung tissue histology and morphometric analysis}

Paraffin-embedded sections of tissues were stained with hematoxylin-eosin and examined by light microscopy at a total magnification of $100 \times$. Interalveolar wall distance was measured as mean linear intercept (MLI), defined as the total length of the test line divided by the number of alveolar walls intersecting it. ${ }^{19}$ Alveolar density was measured as mean alveolar number (MAN), defined as the number of alveoli in each field. ${ }^{19}$ MLI and MAN were calculated for each sample based on ten random fields.

\section{Levels of MMP2 and MMP9 proteins in lung tissue}

Lung tissues were homogenized and lysed. Nuclear and cytoplasmic fractions were prepared as previously described. ${ }^{20}$ The cell lysates ( $20 \mu \mathrm{g}$ for each lane) were subjected to $10 \%$ polyacrylamide gel electrophoresis (PAGE), and the separated protein was subsequently transferred onto a nitrocellulose membrane by electroblotting. The membrane was blocked for 1 hour at room temperature with blocking solution. The blot was then incubated overnight at $4^{\circ} \mathrm{C}$ with mouse anti-MMP2 antibody (1:500; Abcam PLC, Cambridge, UK) or anti-MMP9 antibody (1:500; Abcam PLC). The primary antibody was removed by washing the blot three times, and the membrane was next incubated with secondary antibody (1:2,000 dilution) for 2 hours at room temperature. The signals were detected using enhanced chemiluminescence (GE Healthcare UK Ltd, Little Chalfont, UK), and the protein bands were desitometrically analyzed with $\beta$-actin as a loading control (Metamorph/ Evolution MP 5.0/B X51, Olympus, US). 
To complement these Western blotting studies, we also examined protein signal intensity in situ using immunohistochemistry of lung tissue sections. Sections were cleared of paraffin, endogenous peroxidases were blocked using $3 \% \mathrm{H}_{2} \mathrm{O}_{2}$, and sections were washed and incubated with rabbit serum for 10 minutes at room temperature. Sections were then incubated overnight at $4^{\circ} \mathrm{C}$ with mouse antibody against MMP2 (1:50; Abcam) or MMP9 (1:50; Abcam). Finally, sections were incubated with biotinylated rabbit anti-mouse or goat anti-rabbit immunoglobulin G (IgG) (1:2,000; Santa Cruz Biotechnology Inc, Dallas, TX, USA). Sections were stained with diaminobenzidine (Sinopharm, Shanghai, People's Republic of China) according to the manufacturer's instructions. Five sections from each animal were analyzed, and four images were acquired from one randomly selected location per section. Digital photos were analyzed using Image-Pro Plus 6.0; the analyst was blind to group allocation of the tissue sections.

To verify signal specificity for MMP2 and MMP9, sections were incubated with only primary or secondary antibody in parallel with the experimental samples. Positive staining was not observed in any case.

\section{Determination of MMP2 and MMP9 activity in lung tissues}

The resected lung tissues of each group were homogenized and the activity of MMP2 and MMP9 was quantitatively determined using MMP2 and MMP9 Biotrak ${ }^{\mathrm{TM}}$ activity assay kit (GE Healthcare Bio-Sciences Corp., Piscataway, NJ, USA).

\section{Apoptosis analysis}

The alveolar cell type I was isolated as previously described, ${ }^{21}$ the isolated cells were resuspended in phosphate-buffered saline (PBS), and then fixed in ethanol under room temperature overnight. The cells were washed with PBS and resuspended in staining solution $(50 \mathrm{mg} / \mathrm{mL}$ propidium iodide, $1 \mathrm{mg} / \mathrm{mL}$ RNase A, and $0.1 \%$ Triton X-100 in PBS, all purchased from Thermo Fisher Scientific, Waltham, MA, USA). The stained cells were then analyzed for apoptosis with a BD flow cytometer (BD Biosciences, San Jose, CA, USA).

\section{Levels of PPAR $\gamma$, phospho-MAPK and activated NFKB proteins in lung tissue}

Cytoplasmic fractions containing $50 \mu \mathrm{g}$ of total protein were separated by $10 \%$ sodium dodecyl sulfate-polyacrylamide gel electrophoresis (SDS-PAGE) and transferred to nitrocellulose membranes. The membrane was blocked for 1 hour at room temperature with a blocking solution. The blot was then incubated overnight at $4^{\circ} \mathrm{C}$ with mouse anti-di-phosphorylated extracellular-signal-regulated kinases1 and 2 (ERK1/2) (1:500; Abcam), anti-phospho-JNK (c-Jun N-terminal kinase) (1:500; Abcam), or anti-phospho-p38 (1:500; Abcam). After three washing steps, the membrane was incubated with secondary antibody (1:2,000 dilution) for 2 hours at room temperature. The signals were detected using enhanced chemiluminescence (GE Healthcare UK Ltd), and the protein bands were densitometrically analyzed with $\beta$-actin as a loading control (Metamorph/Evolution MP 5.0/B X51).

To determine the level of NFKB activation in lung tis-

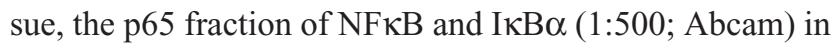
nuclear extracts was analyzed by Western blotting. Nuclear extracts containing $50 \mu \mathrm{g}$ of total protein were resolved by $10 \%$ SDS-PAGE, and NFKB was detected using rabbit polyclonal antibody against NFKB p65 (1:500; Abcam) or anti-IкB $\alpha$ (1:500, Abcam). As a loading control, actin levels were determined using a mouse antibody against actin (1:1,000; Abcam). Blots were incubated with secondary antibody, processed for chemiluminescence, and analyzed as described in this section. Band intensities were quantified using ImageJ software 1.42q and normalized to levels in the control group, as described in this section. Experiments were performed three times for each experimental condition.

\section{Statistical analysis}

Statistical analyses were performed using SPSS version 11.5 (SPSS Inc, Chicago, IL, USA). All data were expressed as means \pm standard deviation (SD). Differences among more than two groups were compared using one-way analysis of variance (ANOVA); differences between two groups were compared using Fisher's least significant difference test. Significance of correlation between two variables was assessed using the Pearson correlation coefficient. The threshold for significance was set at $P<0.05$.

\section{Results \\ PPAR $\gamma$ upregulation by rosiglitazone partially protects against emphysema induced by CS}

In this study, we analyzed the possible effect of PPAR $\gamma$ activation by administration of rosiglitazone on lung morphology when exposed to cigarette smoking. MLI and MAN were measured to compare CS-induced lung emphysema and rosiglitazone-treated emphysema to evaluate the protective effect of PPAR $\gamma$. Cigarette smoke exposure caused significantly decreased expression of PPAR $\gamma$ (Figure 1) and increases in MLI and MAN in the CS group when compared to the control group (Figure 2). When simultaneously 

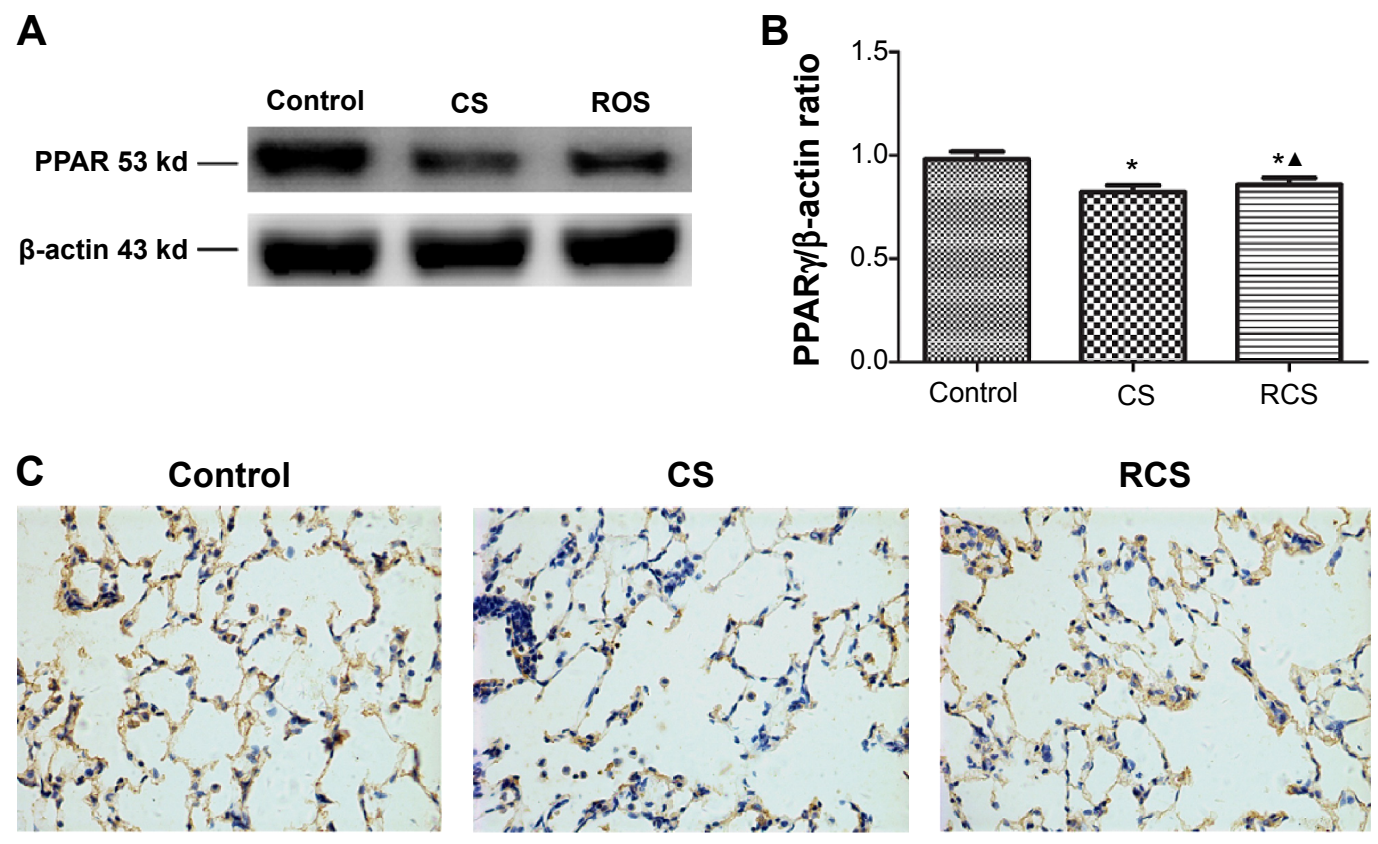

Figure I Effects of cigarette smoke (CS) with the treatment rosiglitazone on the protein expression of PPAR $\gamma$.

Notes: CS stimulation caused the decreased expression of PPAR $\gamma$ (CS group) when compared to the control group, while the treatment of rosiglitazone caused the partial recovery of PPAR $\gamma$ (RCS group). (A) The protein expression of PPAR $\gamma$ as measured by Western blotting; (B) the target protein bands densitometrically analyzed, normalized to $\beta$-actin; (C) the protein expression of PPAR $\gamma$ measured by immunochemistry staining $(\times 400$ magnification) in the control group, CS group, and RCS group. $* P<0.05$, compared with the control group; $\Delta P<0.05$, compared with the CS group.

Abbreviations: PPAR $\gamma$, peroxisome proliferator-activated receptor $\gamma$; RCS, rosiglitazone-cigarette smoke.

treated with rosiglitazone and CS exposure, the changes of emphysema were partially prevented with increased MLI and MAN and the increased expression of PPAR $\gamma$ compared with the CS group (Figures 1 and 2; Table 1).

We compared the lung tissue damage caused by CS in the presence or absence of the PPAR $\gamma$ agonist rosiglitazone. The CS group showed significantly downregulated expression of PPAR $\gamma$ protein (Figure 1) as well as decreases in MLI and MAN (Figure 2), as compared with the control group. The RCS group showed higher levels of PPAR $\gamma$ protein than that of the CS group and lower than that of the control group; both the Western blotting and immunochemistry revealed similar results (Figure 1). Meanwhile, the values of MLI and MAN were higher than those of the CS group and lower than those of the control group (Figure 2).

\section{Rosiglitazone suppressed CS-induced increases in MMP2 and MMP9 protein levels}

In order to assess the inhibitory effect of rosiglitazone on the abnormally enhanced MMP activity associated with emphysema, which thereby helps to restore the
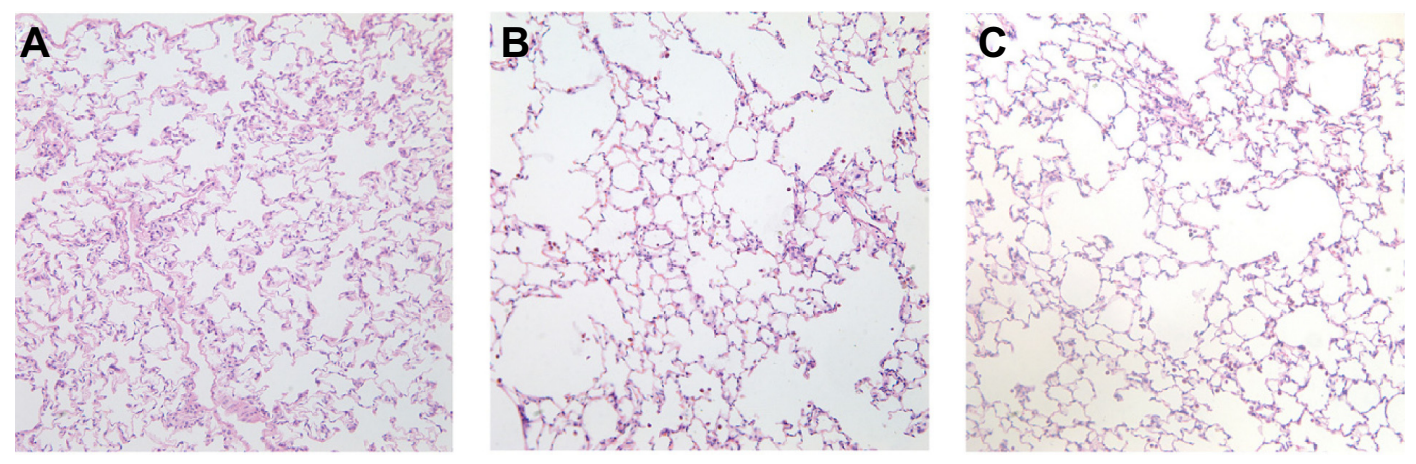

Figure 2 Effects of rosiglitazone on the histopathological changes in lung tissues of cigarette smoke (CS)-induced lung emphysema in rats.

Notes: MLI (mean linear intercept) and MAN (mean alveolar number) were measured to compare the protective effect of PPAR $\gamma$ in CS-induced lung emphysema and rosiglitazone-treated emphysema. When compared to the control group (A), CS caused increased MLI and MAN in the CS group (B). Compared with the CS group (B), rosiglitazone treatment caused decreased MLI and MAN changes (C). $\times 200$ magnification.

Abbreviation: $\operatorname{PPAR} \gamma$, peroxisome proliferator-activated receptor $\gamma$. 
Table I Comparison of emphysematous changes in the emphysema model and the rosiglitazone-treated emphysema model as compared with the control group

\begin{tabular}{llll}
\hline Group & MLI $(\mu \mathrm{m})$ & MAN $(\mathrm{n} / \mathrm{HP})$ & MAA $\left(\mu \mathbf{m}^{2}\right)$ \\
\hline Control group & $45.25 \pm 7.86$ & $105.49 \pm 13.69$ & $6,012.12 \pm 890.48$ \\
CS group & $73.56 \pm 10.28^{*}$ & $50.16 \pm 9.56^{*}$ & $9,618.89 \pm 956.14^{*}$ \\
RCS group & $55.69 \pm 5.35^{* \Delta}$ & $61.17 \pm 10.75^{* \Delta}$ & $8,012.15 \pm 1,168.56^{* \Delta}$ \\
F value & 37.63 & 78.30 & 38.25 \\
\hline
\end{tabular}

Notes: $* P<0.01$, compared with the control group; $\triangle P<0.05$, as compared with the control group.

Abbreviations: CS, cigarette smoke; RCS, rosiglitazone-cigarette smoke; MLI, mean linear intercept; MAA, mean alveolar area; MAN, mean alveolar number

metalloprotease/anti-metalloprotease balance, we measured protein levels and activities of MMP2 and MMP9 in rats exposed to CS with or without treatment of rosiglitazone. The CS group showed significantly higher levels of both protein expression levels (Western blot, Figure 3A, B; immunohistochemistry, Figure 3E), and MMP2 and MMP9 activities (Figure 3C, D), than the other two groups. The protein expression levels and activities of MMP2 and MMP9 in the RCS group were all higher than in the control group (Figure 3).

\section{Rosiglitazone inhibits CS-induced activation of NFKB}

The CS group showed higher levels of NFKB p65 protein than the other two groups; levels in the RCS group were higher than the control group, as determined by Western blot (Figure 4) and immunohistochemistry (Figure 5). In addition to examining levels of NFKB p65, we measured phosphorylation levels of I $\mathrm{B} \alpha$, which inhibited nuclear $\mathrm{NF} \kappa \mathrm{B}$. Levels of I $\mathrm{B} \alpha$ phosphorylation were lower in the CS group than in either of the other two groups; the level in the RCS group was lower than levels in the control group (Figure 4).

\section{Inhibition of NFKB activation by rosiglitazone involves MAPK signaling}

We wanted to identify which one of several pathways known to regulate $\mathrm{NF \kappa B}$ expression also functions as a mediator for the CS-induced activation of transcription factors, as well as for the rosiglitazone-mediated inhibition of this activation. Western blotting showed that levels of phosphorylated p38 and ERK1/2 were higher in the CS group than in the other two groups; these levels in the RCS group were higher than those in the control group (Figure 6). In contract, the levels of phosphorylated JNK in the three groups presented no significant differences between groups.

\section{Effect of rosiglitazone on the apoptosis status of alveolar cells harvested from rats treated with CS}

To quantitatively determine the number of apoptotic cells, we isolated alveolar cells (type I) following the protocol as described previously, ${ }^{21}$ and carried out flow cytometry analysis to determine the ratio of apoptotic cells. As shown in Figure 7, apoptosis indexes in control, CS, and RCS groups were $5.1 \%, 28.8 \%$, and $14.4 \%$, respectively.

\section{Discussion}

In this rat emphysema model, CS exposure upregulated expression of MMP2 and MMP9, creating an imbalance in the metalloprotease/anti-metalloprotease equilibrium, which is associated with histopathological changes in alveoli. These effects were partially but significantly reversed by administering the PPAR $\gamma$ agonist rosiglitazone, together with the CS. Rosiglitazone appears to work by activating NFKB via a MAPK-dependent signaling pathway.

Our observation that exposure to CS induced over-expression of MMP2 and MMP9 is consistent with the widely accepted notions that proteases make a critical contribution to all the pathologic processes detected in the lungs of COPD patients; ${ }^{22-24}$ with more specific findings that expression of MMPs 1-3 and 7-9 are higher in COPD patients than in healthy people; and that MMP9 levels correlated with Global Initiative for Chronic Obstructive Lung Disease (GOLD) stage of pulmonary function test. ${ }^{24}$

Our observation that PPAR $\gamma$ activation reduced the expression of both MMP2 and MMP9, as well as the lung tissue histopathology characteristic of emphysema, is consistent with the idea that PPAR $\gamma$ protects against CS-induced emphysema. Indeed, we have already shown that exposure to CS decreases PPAR $\gamma$ expression and increases inflammatory cytokine expression in bronchial epithelial cells in vivo and in vitro. ${ }^{25}$

Our study adds emphysema to the types of tissue damage and disease against which PPAR $\gamma$ protects by inhibiting production of the extracellular matrix-degrading MMP9. This has already been shown in human bronchial epithelial cells treated with tumor necrosis factor alpha (TNF $\alpha$ ) and phorbol myristate acetate (PMA) in a concentration-dependent manner, ${ }^{26}$ as well as in type 2 diabetic patients treated with rosiglitazone. ${ }^{27}$ Similarly, the PPAR $\gamma$ agonist pioglitazone inhibits the increase in MMP2 and MMP9 expression induced by renal ischemia/reperfusion injury, reducing the severity of renal injury. ${ }^{27}$ Atorvastatin inhibits expression of both MMP9 messenger RNA (mRNA) and protein, while upregulating the 
A

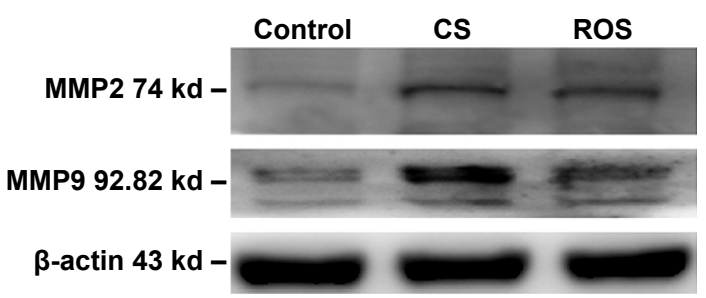

C

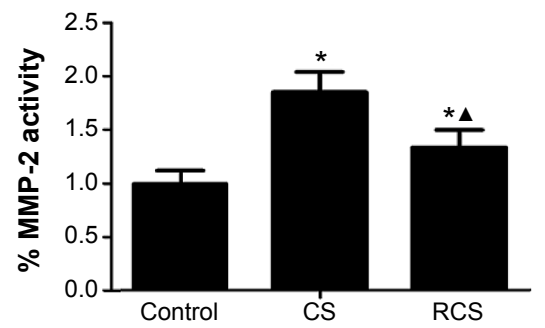

B

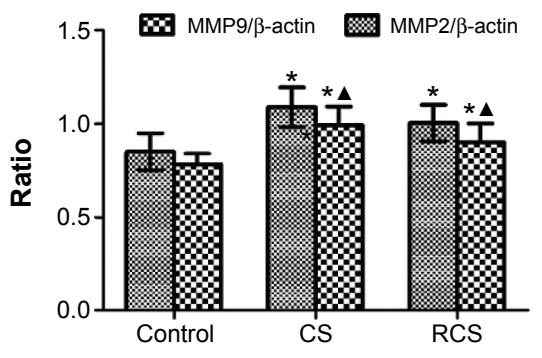

D

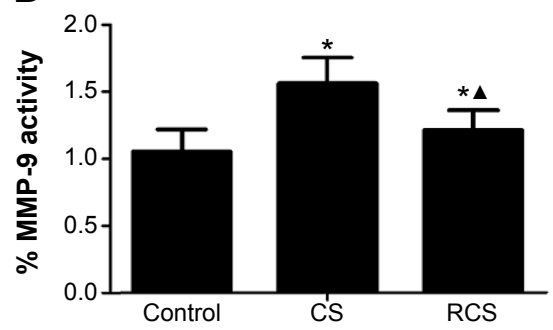

E

Control

CS

RCS

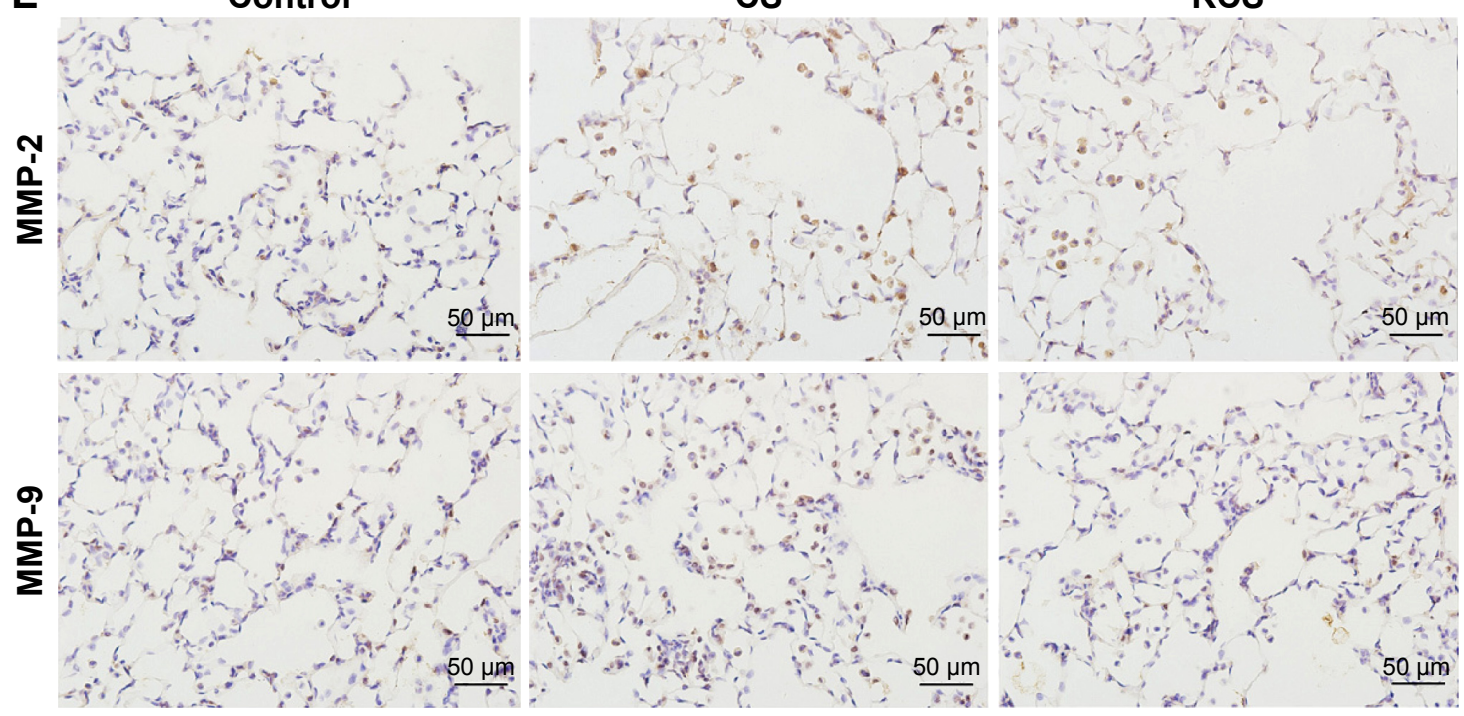

Figure 3 Effects of rosiglitazone on the expression of MMP2 and MMP9 in Cs-induced emphysema in rats.

Notes: Effects of rosiglitazone on the expression of MMP2 and MMP9 in CS-induced emphysema in rats as measured by Western blotting (A). The target protein bands were desitometrically analyzed normalized to $\beta$-actin (B). The activities of MMP2 (C) and MMP9 (D) in each group were determined by using MMP2 and MMP9 Biotrak ${ }^{\text {TM }}$ activity assay. The expression of MMP2 and MMP9 was confirmed by using immunohistochemistry for each group (magnification $\times 400)(E)$. The values presented are the mean \pm SD. $* P<0.05$, compared with the control group; $\Delta P<0.05$, compared with the CS group.

Abbreviations: MMP, metalloprotease; CS, cigarette smoke; SD, standard deviation; RCS, rosiglitazone-cigarette smoke.

expression of all PPAR isoforms; pretreatment with PPAR inhibitors attenuates this inhibition of MMP9 expression. ${ }^{28}$ Our study is the first to extend the possibility of PPAR $\gamma$ protection to emphysema and the imbalance of MMPs in emphysema.

We found that while CS increased NFkB expression, PPAR $\gamma$ activation by rosiglitazone partially inhibited this NFKB upregulation. We observed the inverse trend with expression of $\mathrm{I} \kappa \mathrm{B} \alpha$, a negative regulator of $\mathrm{NF} \kappa \mathrm{B}$. These results are consistent with the idea that $\mathrm{NF \kappa B}$ is a key promoter of inflammation, whose activation in the lower airways of patients with COPD will lead to pulmonary emphysema, ${ }^{29,30}$ which is negatively regulated by PPAR $\gamma$. Once activated, NFKB translocates to the nucleus, where it induces the transcription of proinflammatory genes. Based on experiments in adipose tissue, the RelA subunit of NFKB binds to PPAR $\gamma$ and prevents dimers of PPAR $\gamma$ and retinoid $\mathrm{X}$ receptor from binding to target genes. ${ }^{31}$ This binding event also leads to nuclear export of NFKB, thereby reducing NFKB-mediated inflammatory gene expression. ${ }^{32}$ While 
A

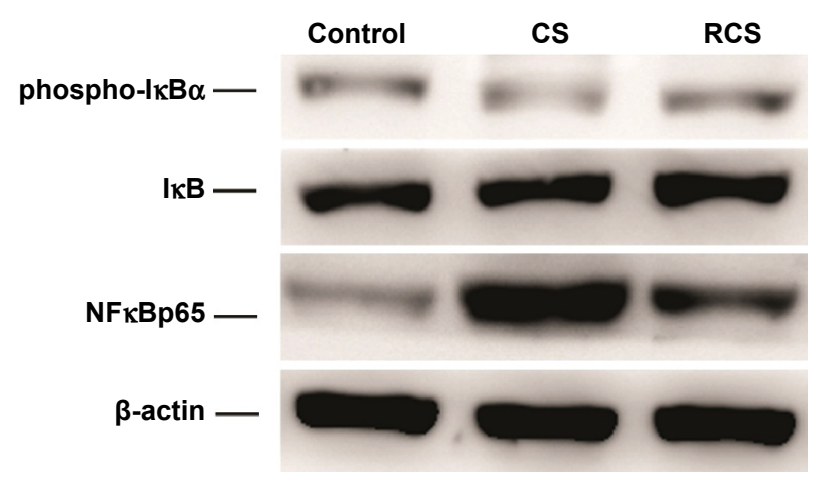

B

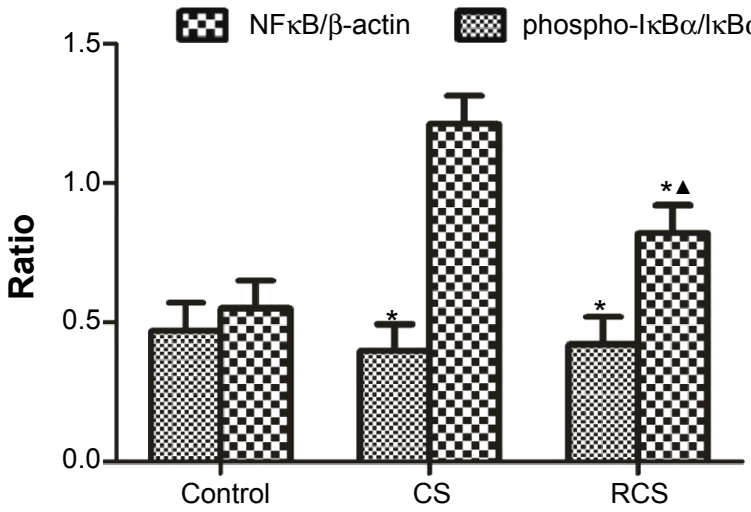

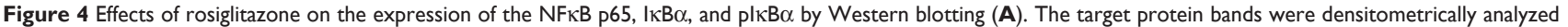
normalized to $\beta$-actin (B).

Notes: $* P<0.05$, compared with the control group; $\Delta P<0.05$, compared with the CS group.

Abbreviations: p, protein; NFKB, nuclear factor kappa-light-chain-enhancer of activated B cells; IкB $\alpha$, nuclear factor of kappa light polypeptide gene enhancer in B-cell inhibitor, alpha; CS, cigarette smoke; RCS, rosiglitazone-cigarette smoke.
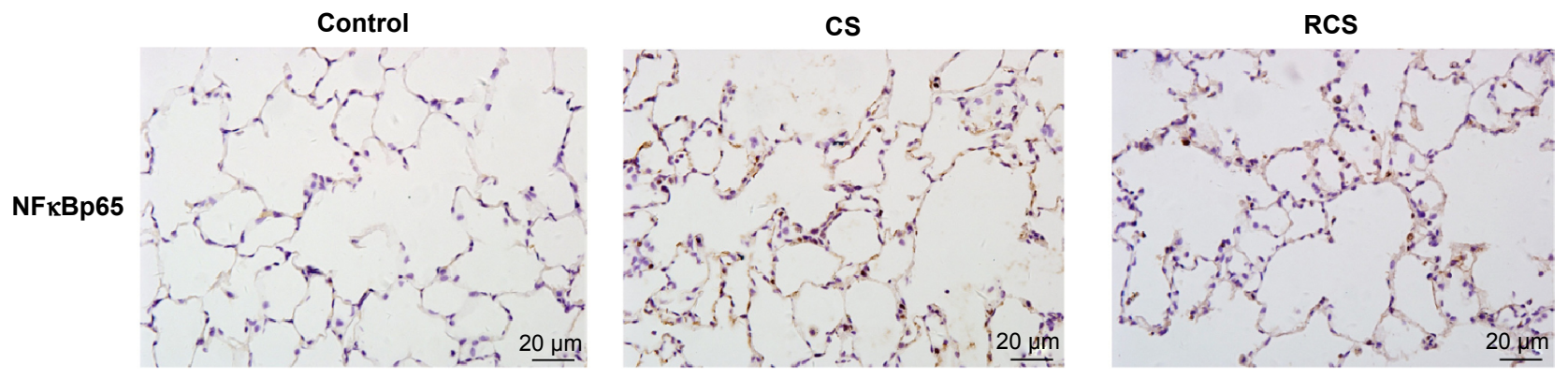

Figure 5 Effects of rosiglitazone on the expression of the NFKB p65 in alveolar epithelial cells as determined by immunohistochemistry.

Abbreviations: p65, protein 65; NFkB, nuclear factor kappa-light-chain-enhancer of activated B cells; CS, cigarette smoke; RCS, rosiglitazone-cigarette smoke.

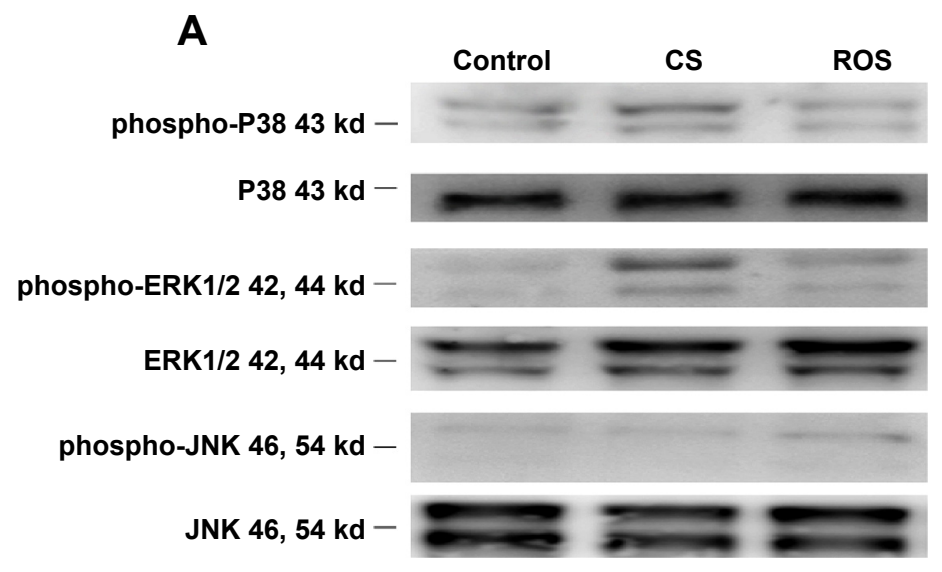

B

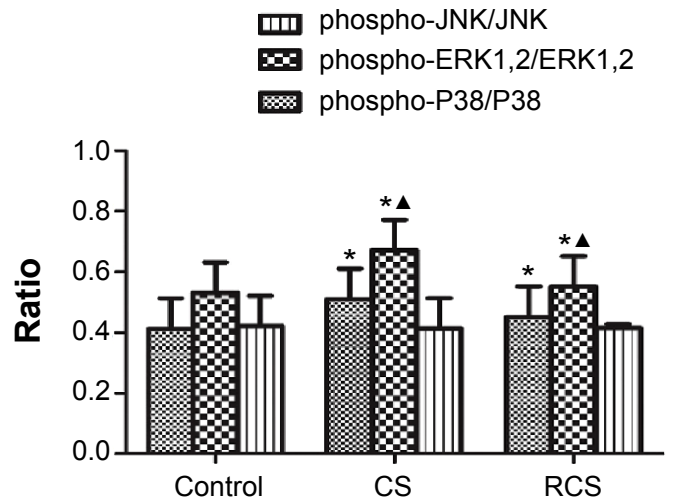

Figure 6 Effects of rosiglitazone on the signaling pathway of MAPK.

Notes: The expression of P38, phospho-P38, ERKI/2, phospho-ERKI/2, JNK, and phospho-JNK was measured by Western blotting (A), and the target protein bands were densitometrically analyzed normalized to $\beta$-actin (B). $* P<0.05$, compared with the control group; $\mathbf{A}<0.05$, compared with the CS group.

Abbreviations: MAPK, mitogen-activated protein kinase; ERKI/2, extracellular signal-regulated kinase-I and -2; JNK, c-Jun N-terminal kinase; CS, cigarette smoke; RCS, rosiglitazone-cigarette smoke. 

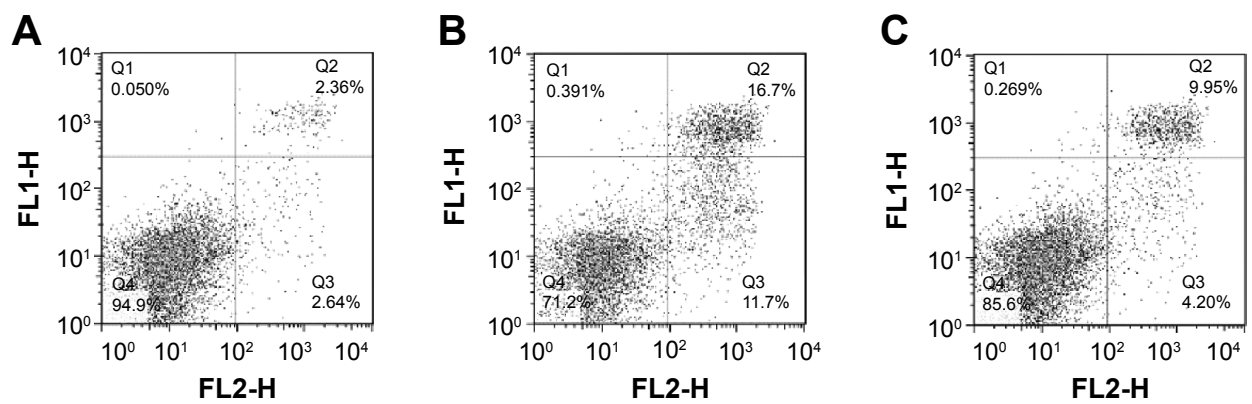

Figure 7 Effect of rosiglitazone on apoptosis status of alveolar cells (type I) isolated from control group (A), CS group (B), and RCS group (C). Abbreviations: CS, cigarette smoke; RCS, rosiglitazone-cigarette smoke.

signal transduction "cross-talk" between PPAR $\gamma$ and NFKB has been documented in several types of tissue damage and disease, this is the first report suggesting that such cross-talk also occurs in CS-induced emphysema.

Evidence of such cross-talk is consistent with previous work from our laboratory in macrophages harvested from rats exposed to CS for 3 months in vivo, which showed that rosiglitazone counteracted CS-induced leukotriene B4 (LTB4) and interleukin 8 (IL8) release and PPAR $\gamma$ downregulation, markedly lowering the expression of toll-like receptor 4 (TLR4) and TLR $2,{ }^{25}$ and consistent with a study in a mouse model of polymicrobial sepsis due to cecal ligation and puncture..$^{33}$ In the latter mouse model, sepsis upregulated $\mathrm{NF \kappa B}$ expression and downregulated I $\mathrm{KB} \alpha$ expression; both changes were partially inhibited by pioglitazone.

In order to assess what signaling pathways lead to NFKB activation in emphysema, we analyzed levels of p38 MAPK, ERK1/2, and JNK after exposure to CS in the presence or absence of rosiglitazone. We found that smoke exposure increased phosphorylation of ERK1/2 and p38 and decreased PPAR $\gamma$ expression, with no obvious effect on JNK phosphorylation. Exposure to smoke in the presence of rosiglitazone led to smaller increases in phosphorylation of ERK $1 / 2$ and p38. These results provide the first evidence that CS activates PPAR $\gamma$ by triggering the phosphorylation of ERK $1 / 2$ and $\mathrm{p} 38$ MAPK. These findings extend the results of a previous study indicating that MAPK kinase signaling mediates some of the effects of CS on cytokine production. ${ }^{34}$ How rosiglitazone inhibits the smoke-induced activation of ERK1/2 and p38 requires further study.

The mechanism of PPAR $\gamma$ regulation observed in the current study in CS-induced emphysema appears to be analogous to that described for other disease models. ${ }^{35,36}$ In a study of apoptosis regulation of human neuroblastoma cells, the PPAR $\gamma$ agonist 15-deoxy-delta 12,14-prostaglandin J2 induced PPAR $\gamma$ expression and activated ERK2, while both these changes were partially inhibited by the PPAR $\gamma$ antagonist GW9662. ${ }^{37}$ In a study exploring the mechanism of the rosiglitazone inhibition of TNF $\alpha$ and gamma interferon (IFN $\gamma$ ) inflammatory effects in human endothelial cells, rosiglitazone attenuated the inflammatory response by inhibiting ERK1/2 phosphorylation. ${ }^{38}$ Rosiglitazone also rapidly inhibited the homocysteine-induced phosphorylation of ERK1/2 and p38 MAPK in endothelial cells and vascular smooth muscle cells. ${ }^{39}$

This mechanism of PPAR $\gamma$ regulation may not be universal. In a mouse model of polymicrobial sepsis, an increase in nuclear levels of phosphorylated ERK1/2 correlated with a decrease in PPAR $\gamma$ phosphorylation in peripheral blood mononuclear cells; in lung tissue, however, the increase in phosphorylated ERK1/2 was associated with an increase in PPAR $\gamma$ phosphorylation. ${ }^{40}$ In MCF7 breast cancer cells, $\alpha$-eleostearic acid simultaneously inhibited phosphorylation of ERK1/2 and PPAR $\gamma$ in a time-dependent manner. ${ }^{41}$ The PPAR $\gamma$ agonist troglitazone upregulated PPAR $\gamma$ expression in the human lung cancer cell lines NCI-H23 and CRL-2066, as well as to a lesser extent in the normal human lung cell line CRL-202. ${ }^{42}$ However, in contrast to the results observed in the present study, these troglitazoneinduced increases in PPAR $\gamma$ expression were associated with increases in the levels of phosphorylated ERK1/2 and p38 and with decreases in stress-activated protein kinase (SAPK)/ JNK activity. The difference between these results and those in our study and related work highlights the multiple signaling pathways that regulate PPAR $\gamma$ activity and the likelihood that the precise pathway involved depends on the physiological process (eg, inflammation, aging, proliferation) and the stimulus (eg, cigarette smoking, inflammatory cytokines).

\section{Conclusion}

In summary, our animal model suggests that CS works via signaling pathways dependent on MAPK and NFKB 
pathways to activate PPAR $\gamma$, leading in turn to excess MMP2 and MMP9 activity. This metalloprotease/anti-metalloprotease imbalance plays a large part in the emphysematous changes induced by CS. These mechanistic insights may help lead to new therapies for COPD and emphysema.

\section{Acknowledgment}

This research was supported by project grant 2012BAI05B01 from the Ministry of Science and Technology of the People's Republic of China.

\section{Author contributions}

GH helped design the study, establish the animal model, collect and analyze samples, and write the manuscript. YY and DH helped establish the animal model, performed Western blotting, immunohistochemistry analyses. YY and DH also helped analyse data and revise the manuscript. QYW and JK contributed to study planning, analyse and interpret data, review and revise the manuscript. All authors have approved the final version of this article to be published and agreed to be accountable for all aspects of the work in ensuring the questions related to the accuracy or integrity of any part of the work.

\section{Disclosure}

The authors report no conflicts of interest in this work.

\section{References}

1. Vestbo J, Hurd SS, Agustí AG, et al. Global strategy for the diagnosis, management, and prevention of chronic obstructive pulmonary disease GOLD executive summary. Am J Respir Crit Care Med. 2013;187(4):347-365.

2. Angelis N, Porpodis K, Zarogoulidis P, et al. Airway inflammation in chronic obstructive pulmonary disease. J Thorac Dis. 2014;6(Suppl 1): S167-S172.

3. Mocchegiani E, Giacconi R, Costarelli L. Metalloproteases/anti-metalloproteases imbalance in chronic obstructive pulmonary disease: genetic factors and treatment implications. Curr Opin Pulm Med. 2011;17(Suppl 1):S11-S19.

4. Churg A, Zhou S, Wright JL. Series "matrix metalloproteinases in lung health and disease": matrix metalloproteinases in COPD. Eur Respir J. 2012;39(1):197-209.

5. Dhariwal J, Tennant RC, Hansell DM, et al. Smoking cessation in COPD causes a transient improvement in spirometry and decreases micronodules on high-resolution CT imaging. Chest. 2014;145(5): $1006-1015$.

6. Coxson HO, Dirksen A, Edwards LD, et al; Evaluation of COPD Longitudinally to Identify Predictive Surrogate Endpoints (ECLIPSE) Investigators. The presence and progression of emphysema in COPD as determined by CT scanning and biomarker expression: a prospective analysis from the ECLIPSE study. Lancet Respir Med. 2013;1(2):129-136.

7. Carolan BJ, Sutherland ER. Clinical phenotypes of chronic obstructive pulmonary disease and asthma: Recent advances. J Allergy Clin Immunol. 2013;131(3):627-634.

8. Ahmadian M, Suh JM, Hah N, et al. PPAR $\gamma$ signaling and metabolism: the good, the bad and the future. Nat Med. 2013;19(5):557-566.
9. Kostadinova R, Wahli W, Michalik L. PPARs in diseases: control mechanisms of inflammation. Curr Med Chem. 2005;12(25):2995-3009.

10. Belvisi MG, Hele DJ, Birrell MA. Peroxisome proliferator-activated receptor gamma agonists as therapy for chronic airway inflammation. Eur J Pharmacol. 2006;533(1-3):101-109.

11. Yoo SH, Abdelmegeed MA, Song BJ. Activation of PPARalpha by Wy-14643 ameliorates systemic lipopolysaccharide-induced acute lung injury. Biochem Biophys Res Commun. 2013;436(3):366-371.

12. Lu X, Bijli KM, Ramirez A, Murphy TC, Kleinhenz J, Hart CM. Hypoxia downregulates PPARgamma via an ERK1/2-NF-kappaBNox4-dependent mechanism in human pulmonary artery smooth muscle cells. Free Radic Biol Med. 2013;63:151-160.

13. Wechsler ME, Laviolette M, Rubin AS, et al; Asthma Intervention Research 2 Trial Study Group. Bronchial thermoplasty: long-term safety and effectiveness in patients with severe persistent asthma. J Allergy Clin Immunol. 2013;132(6):1295-1302.

14. Kim SH, Hong JH, Lee YC. Ursolic acid, a potential PPARgamma agonist, suppresses ovalbumin-induced airway inflammation and Penh by down-regulating IL-5, IL-13, and IL-17 in a mouse model of allergic asthma. Eur J Pharmacol. 2013;701(1-3):131-143.

15. Lea S, Plumb J, Metcalfe H, et al. The effect of peroxisome proliferatoractivated receptor-gamma ligands on in vitro and in vivo models of COPD. Eur Respir J. 2014;43(2):409-420.

16. Yamasaki S, Nakashima T, Kawakami A, et al. Functional changes in rheumatoid fibroblast-like synovial cells through activation of peroxisome proliferator-activated receptor gamma-mediated signalling pathway. Clin Exp Immunol. 2002;129(2):379-384.

17. Ko GJ, Kang YS, Han SY, et al. Pioglitazone attenuates diabetic nephropathy through an anti-inflammatory mechanism in type 2 diabetic rats. Nephrol Dial Transplant. 2008;23(9):2750-2760.

18. Miyahara T, Schrum L, Rippe R, et al. Peroxisome proliferatoractivated receptors and hepatic stellate cell activation. $J$ Biol Chem. 2000;275(46):35715-35722.

19. Xu L, Cai BQ, Zhu YJ. Pathogenesis of cigarette smoke-induced chronic obstructive pulmonary disease and therapeutic effects of glucocorticoids and $\mathrm{N}$-acetylcysteine in rats. Chin Med $J$ (Engl). 2004;117(11):1611-1619.

20. Qi B, Chen HL, Shang D, Dong Y, Zhang GX, Yu L. Effects of hypoxia-inducible factor-1alpha and matrix metalloproteinase-9 on alveolar-capillary barrier disruption and lung edema in rat models of severe acute pancreatitis-associated lung injury. Exp Ther Med. 2014;8: 899-906.

21. Gonzalez RF, Dobbs LG. Isolation and culture of alveolar epithelial Type I and Type II cells from rat lungs. Methods Mol Biol. 2013;945:145-159.

22. Mocchegiani E, Giacconi R, Costarelli L. Metalloproteases/antimetalloproteases imbalance in chronic obstructive pulmonary disease: genetic factors and treatment implications. Curr Opin Pulm Med. 2011;17(Suppl 1):S11-S19.

23. Antunes MA, Rocco PR. Elastase-induced pulmonary emphysema: insights from experimental models. An Acad Bras Cienc. 2011;83(4):1385-1396.

24. Navratilova Z, Zatloukal J, Kriegova E, Kolek V, Petrek M. Simultaneous up-regulation of matrix metalloproteinases 1, 2, 3, 7, 8, 9 and tissue inhibitors of metalloproteinases 1, 4 in serum of patients with chronic obstructive pulmonary disease. Respirology. 2012;17(6):1006-1012.

25. Yin Y, Hou G, Li ER, Wang QY, Kang J. Regulation of cigarette smoke-induced toll-like receptor 4 expression by peroxisome proliferator-activated receptor-gamma agonists in bronchial epithelial cells. Respirology. 2013;18(Suppl 3):30-39.

26. Hetzel M, Walcher D, Grüb M, Bach H, Hombach V, Marx N. Inhibition of MMP-9 expression by PPARgamma activators in human bronchial epithelial cells. Thorax. 2003;58(9):778-783.

27. Marx N, Froehlich J, Siam L, et al. Antidiabetic PPAR gammaactivator rosiglitazone reduces MMP-9 serum levels in type 2 diabetic patients with coronary artery disease. Arterioscler Thromb Vasc Biol. $2003 ; 23(2): 283-288$. 
28. Han L, Li MG, Liu YX, Han CG, Ye P. Atorvastatin may delay cardiac aging by upregulating peroxisome proliferator-activated receptors in rats. Pharmacology. 2012;89(1-2):74-82.

29. Kobayashi Y, Wada H, Rossios C, et al. A novel macrolide solithromycin exerts superior anti-inflammatory effect via NF-kappaB inhibition. J Pharmacol Exp Ther. 2013;345(1):76-84.

30. Brown V, Elborn JS, Bradley J, Ennis M. Dysregulated apoptosis and NFkappaB expression in COPD subjects. Respir Res. 2009;10:24.

31. Suzawa M, Takada I, Yanagisawa J, et al. Cytokines suppress adipogenesis and PPAR-function through the TAK1/TAB1/NIK cascade. Nat Cell Biol. 2003;5(3):224-230.

32. Kelly D, Campbell J, King TP, et al. Commensal anaerobic gut bacteria attenuate inflammation by regulating nuclear-cytoplasmic shuttling of PPAR-gamma and RelA. Nat Immunol. 2004;5(1):104-112.

33. Kaplan J, Nowell M, Chima R, Zingarelli B. Pioglitazone reduces inflammation through inhibition of NF-kappa B in polymicrobial sepsis. Innate Immun. 2014;20(5):519-528.

34. Mao J, Liu J, Pang X, et al. Nicotine induces the expression of C-reactive protein via MAPK-dependent signal pathway in U937 macrophages. Mol Cells. 2012;34(5):457-461.

35. Burgermeister E, Seger R. MAPK kinases as nucleo-cytoplasmic shuttles for PPAR gamma. Cell Cycle. 2007;6(13):1539-1548.

36. Burns KA, Vanden Heuvel JP. Modulation of PPAR activity via phosphorylation. Biochim Biophys Acta. 2007;1771(8):952-960.

37. Kim EJ, Park KS, Chung SY, et al. Peroxisome proliferator-activated receptor-gamma activator 15-deoxy-Delta(12,14)-prostaglandin $\mathrm{J}(2)$ inhibits neuroblastoma cell growth through induction of apoptosis: Association with extracellular signal-regulated kinase signal pathway. J Pharmacol Exp Ther. 2003;307(2):505-517.
38. Lombardi A, Cantini G, Piscitelli E, et al. A new mechanism involving ERK contributes to rosiglitazone inhibition of tumor necrosis factoralpha and interferon-gamma inflammatory effects in human endothelial cells. Arterioscler Thromb Vasc Biol. 2008;28(4):718-724.

39. Bai YP, Liu YH, Chen J, et al. Rosiglitazone attenuates NF-kappaBdependent ICAM-1 and TNF-alpha production caused by homocysteine via inhibiting ERK1/2/p38MAPK activation. Biochem Biophys Res Commun. 2007;360(1):20-26.

40. Kaplan JM, Hake PW, Denenberg A, Nowell M, Piraino G, Zingarelli B. Phosphorylation of extracellular signal-regulated kinase (ERK)-1/2 Is associated with the downregulation of peroxisome proliferatoractivated receptor (PPAR)- $\gamma$ during polymicrobial sepsis. Mol Med. 2010;16(11-12):491-497.

41. Moon HS, Guo DD, Lee HG, et al. Alpha-eleostearic acid suppresses proliferation of MCF-7 breast cancer cells via activation of PPARgamma and inhibition of ERK 1/2. Cancer Sci. 2010;101(2): 396-402.

42. Li M, Lee TW, Mok TS, Warner TD, Yim AP, Chen GG. Activation of peroxisome proliferator-activated receptor-gamma by troglitazone (TGZ) inhibits human lung cell growth. $J$ Cell Biochem. 2005;96(4):760-774.
International Journal of COPD

\section{Publish your work in this journal}

The International Journal of COPD is an international, peer-reviewed journal of therapeutics and pharmacology focusing on concise rapid reporting of clinical studies and reviews in COPD. Special focus is given to the pathophysiological processes underlying the disease, intervention programs, patient focused education, and self management protocols.

\section{Dovepress}

This journal is indexed on PubMed Central, MedLine and CAS. The manuscript management system is completely online and includes a very quick and fair peer-review system, which is all easy to use. Visit http://www.dovepress.com/testimonials.php to read real quotes from published authors. 